\title{
Resultados agronômicos e qualitativos da nova cultivar de trigo 'BRS 296'
}

\author{
Agronomic and qualitative results of the new wheat cultivar 'BRS 296' \\ Pedro Luiz Scheeren ${ }^{I^{*}}$ Eduardo Caierão $^{\mathrm{I}}$ Márcio Só e Silva ${ }^{\mathrm{I}}$ Luiz Eichelberger ${ }^{\mathrm{II}}$ \\ Alfredo do Nascimento Junior ${ }^{\mathrm{I}}$ Martha Zavariz de Miranda ${ }^{\mathrm{II}}$
}

\begin{abstract}
A cultivar de trigo 'BRS 296', desenvolvida pela Embrapa, foi registrada para cultivo em 2009. Originou-se do cruzamento entre o genitor feminino PF 93232 e o genitor masculino COOK*4/VPM1, realizado em telado, na Embrapa Trigo, no verão de 1992/1993. As gerações segregantes foram conduzidas pelo método genealógico até a fixação da linhagem, nomeada de PF 990283. Caracteriza-se pela sua excelente sanidade foliar e de espiga e pela estabilidade de produção. Preliminarmente, está enquadrada na classe comercial Pão e seu cultivo é recomendado para todas as regiões tritícolas do Brasil.
\end{abstract}

Palavras-chave: melhoramento, germoplasma, cereais, Triticum aestivum.

\section{ABSTRACT}

The wheat cultivar BRS 296, developed by Embrapa, was released to production in 2009. It was originated of cross between PF 93232 and COOK*4/VPM1, carried out in green-house, in the summer of 1992/1993. The segregate generations were conducted by genealogic method until homozigose of genotype, named PF 990283. It has excellent leave and spike sanity and production stability. Preliminarily, it was classified as Bread Wheat and is recommended to all wheat regions of Brazil.

Key words: breeding, germoplasm, cereal, Triticum aestivum.
O sucesso do melhoramento genético do trigo no país tem sido obtido tanto pelo método de cruzamentos, quanto pelo de introduções, especialmente de cultivares mexicanas. Poucos resultados foram obtidos por mutação. Como prova da contribuição genética dos programas de melhoramento de trigo, para a cadeia produtiva desse cereal, no Brasil, de 1922 até 2003, foram recomendadas 429 cultivares (SOUSA, 2004). Somente no Rio Grande do Sul, por exemplo, estavam recomendadas para cultivo, no ano de 2008, mais de 50 cultivares de diferentes obtentores (REUNIÃO, 2008).

O programa de melhoramento genético de trigo da Embrapa tem como meta disponibilizar cultivares com desempenho agronômico competitivo e aptas aos diferentes segmentos da indústria moageira. Este trabalho teve como objetivo divulgar para a sociedade científica as características da nova cultivar de trigo 'BRS 296'.

A cultivar de trigo 'BRS 296' resultou do cruzamento entre o genitor feminino PF 93232 e o genitor masculino COOK*4/VPM1, realizado em telado, na Embrapa Trigo, no verão de 1992/1993. As gerações segregantes foram conduzidas pelo método genealógico, no inverno e verão dos anos

\footnotetext{
IEmbrapa Trigo, Melhoramento Vegetal, Rodovia BR 285, km 294, CP 451, 99001-970, Passo Fundo, RS, Brasil. E-mail: scheeren@cnpt.embrapa.br.*Autor para correspondência.

IEmbrapa Trigo, Produção de Sementes, Passo Fundo, RS, Brasil.

IIIEmbrapa Trigo, Qualidade Tecnológica, Passo Fundo, RS, Brasil.
} 
subsequentes, até a fixação da linhagem em geração $\mathrm{F}_{10}$, no ano de 1999 , quando passou a ser denominada de 'PF 990283'. Nas gerações $F_{2}, F_{4}, F_{5}, F_{6}$ e $F_{7}$, foram selecionadas plantas resistentes ao oídio e à ferrugem da folha em condições de campo, sob inoculação artificial dos patógenos. Em cada ciclo de seleção, foram selecionadas as plantas de grão duro e vermelho, com bom enchimento e com sanidade em relação às doenças de espiga. O histórico de seleção da cultivar foi F46187902F-5F-901F-903F-902F-453F-300F-6501F-0F.

A determinação dos descritores da cultivar de trigo 'BRS 296' foi realizada nos ensaios de Distinguibilidade, Homogeneidade e Estabilidade (DHE), conduzidos pela Embrapa Trigo nos anos de 2003, 2004 e 2005, no Município de Passo Fundo, Rio Grande do Sul (RS), localizado em latitude de $28^{\circ} 15^{\prime} 46^{\prime \prime}$, longitude de $52^{\circ} 24^{\prime} 24^{\prime \prime}$ e altitude de $687 \mathrm{~m}$. Como metodologia de avaliação, foram avaliadas 2.500 plantas, divididas em duas repetições. As características intrínsecas da cultivar estão descritas na tabela 1. 'BRS 296’ é um trigo pertencente ao grupo bioclimático de primavera, de hábito semiereto e estatura média (média de $95 \mathrm{~cm}$ ). Possui ciclo médio, com período médio da emergência ao espigamento de 80 dias e do espigamento à maturação de 50 dias (Tabela 1).

A cultivar 'BRS 296' caracteriza-se por ser moderadamente resistente ao crestamento, à geada em fase vegetativa e à germinação na espiga. Apresenta comportamento moderadamente suscetível à debulha natural e ao acamamento. Com relação às principais doenças da cultura, caracteriza-se por ser moderadamente resistente à septoriose das glumas (Stagonospora nodorum), à giberela (Gibberella zeae), ao vírus do mosaico do trigo (VMT) e é resistente ao

Tabela 1 - Descritores biológicos e morfológicos da cultivar de trigo 'BRS 296' oriundos do ensaio para determinação da Distinguibilidade, Homogeneidade e Estabilidade (DHE), conduzido nos anos de 2002, 2003 e 2004.

\begin{tabular}{|c|c|c|}
\hline Órgão & Característica & Descrição \\
\hline \multirow{6}{*}{ Planta } & Grupo bioclimático & Trigo de Primavera \\
\hline & Hábito & Semi-ereto \\
\hline & Altura & Média (95cm) \\
\hline & Ciclo Total & Precoce - Em torno de 130 dias \\
\hline & Sub-período Emergência/Espigamento & Média de 80 dias \\
\hline & Sub-período Espigamento/Maturação & Média 50 dias \\
\hline \multirow{3}{*}{ Folha } & Posição da folha bandeira & Intermediária/Ereta \\
\hline & Coloração das aurículas & Heterogêneas \\
\hline & Cerosidade da bainha & Fraca a Forte \\
\hline \multirow{4}{*}{ Colmo } & Forma do nó superior & Quadrado/Comprido \\
\hline & Cerosidade do pedúnculo & Fraca a Forte \\
\hline & Espessura das paredes & Delgada \\
\hline & Diâmetro & Fino \\
\hline \multirow{4}{*}{ Espiga } & Forma & Fusiforme \\
\hline & Comprimento & Semi/longa (85 a 94mm) \\
\hline & Coloração & Clara \\
\hline & Arista & Aristada \\
\hline \multirow{5}{*}{ Gluma } & Comprimento & Médio (7 a 8mm) \\
\hline & Largura & Média (maior ou igual a 3mm) \\
\hline & Pilosidade & Glabra (sem pelos) \\
\hline & Forma do ombro & Elevado \\
\hline & Comprimento do dente & Longo (maior ou igual a 7mm) \\
\hline \multirow{4}{*}{ Grão } & Forma & Ovalado \\
\hline & Comprimento & Médio (6 a 7mm) \\
\hline & Coloração & Vermelho \\
\hline & Textura & Duro \\
\hline
\end{tabular}

Ciência Rural, v.40, n.7, jul, 2010. 
oídio (Blumeria graminis). Com relação à ferrugem da folha (Puccinia triticina), apresenta reação de resistência no campo, com RPA (resistência de planta adulta).

O desempenho agronômico e qualitativo da cultivar 'BRS 296' foi avaliado durante seis anos de experimentação, em diferentes ambientes dos Estados do Rio Grande do Sul, de Santa Catarina, do Paraná, do Mato Grosso do Sul e de São Paulo. Nos anos de 2001, 2002 e 2003, fez parte dos ensaios preliminares, desenvolvidos regionalmente. Em 2002, 2003 e 2004, passou a compor o ensaio VCU (Valor de Cultivo e Uso), conduzido em nível nacional e utilizado para fins de registro junto ao Ministério da Agricultura, sendo avaliado em 47 locais.

'BRS 296' apresentou rendimento médio de grãos de $3.669 \mathrm{~kg} \mathrm{ha}^{-1}$ na média dos ensaios conduzidos de 2003 a 2005, superando em $1 \%$ a média das cultivares testemunhas ‘Ônix’ e ‘BRS 208'. Na análise anual, somente em 2003 seu desempenho não foi superior à média das testemunhas, em que expressou rendimento médio de 3.816 kg ha ${ }^{-1}$. Em 2005, foi observado o seu melhor desempenho, superando a média das testemunhas em 12\% (Tabela 2).

As amostras oriundas da experimentação durante os anos de ensaio VCU foram utilizadas para a caracterização qualitativa da cultivar. Na média de 34 amostras analisadas, em diferentes Estados, a força de glúten da cultivar 'BRS 296' foi de $21910^{-4} \mathrm{~J}$, oscilando de 180 10-4 J, em Santa Catarina, a 285 10-4 J, em São
Paulo (Tabela 3). Esse comportamento fez com que fosse lançado em 2009, preliminarmente, como trigo da classe Pão. Esse enquadramento provisório deve-se ao fato de que poucas amostras da cultivar são analisadas até o momento do lançamento. Se ao longo dos primeiros anos de cultivo o desempenho qualitativo da cultivar não for coerente com os dados experimentais (o que é possível, já que esta estará sujeita a um número muito maior de microclimas de cultivo em comparação com a fase de experimentação), a classificação pode ser alterada.

'BRS 296' apresentou média de extração de farinha em moinho experimental de 57\%, chegando a atingir 60\% nos Estados do Rio Grande do Sul e Santa Catarina (Tabela 3). Os valores de tenacidade (P) e extensibilidade (L) observados foram de 84, na média geral das amostras, revelando perfil de P/L igual a 1,1, para a finalidade de panificação. Em relação à cor de farinha, apresentou média de "L"=92,6; de "a"=0,0; e de "b"=10,2, o que indica coloração normal.

A cultivar de trigo 'BRS 296', lançada em 2009, por ocasião da 3ํㅡㄹ Reunião da Comissão Brasileira de Pesquisa de Trigo e Triticale, realizada em Veranópolis, RS, foi indicada para cultivo em todas as regiões tritícolas do Brasil, desde o Rio Grande do Sul até São Paulo, sob regime de sequeiro. Foi registrada, no Ministério da Agricultura, Pecuária e Abastecimento, sob o número 25709. 'BRS 296' é o primeiro trigo de oferta pública da Embrapa após o término da parceria com a Fundação Pró-sementes de Apoio à Pesquisa.

Tabela 2 - Rendimento de grãos ( $\mathrm{kg} \mathrm{ha}^{-1}$ ) da cultivar de trigo ‘BRS 296' e das testemunhas 'Ônix’ e de 'BRS 208' e percentual relativo de desempenho na média dos locais de experimentação conduzidos nos anos de 2003, 2004 e 2005, em relação à média das testemunhas.

\begin{tabular}{|c|c|c|c|c|c|c|c|c|}
\hline \multirow{2}{*}{ Cultivares } & \multicolumn{2}{|c|}{---------200233--------- } & \multicolumn{2}{|c|}{---------20034'--------- } & \multicolumn{2}{|c|}{--------2004 } & \multicolumn{2}{|c|}{----Média 2002-2004---- } \\
\hline & kg ha ${ }^{-1}$ & $\%^{1}$ & $\mathrm{~kg} \mathrm{ha}^{-1}$ & $\%^{1}$ & $\mathrm{~kg} \mathrm{ha}^{-1}$ & $\%^{1}$ & $\mathrm{~kg} \mathrm{ha}^{-1}$ & $\%^{1}$ \\
\hline 'BRS 296' & 3.816 & 90 & 3.822 & 102 & 3.368 & 112 & 3.669 & 101 \\
\hline ‘Ônix’ & 4.283 & 100 & 3.608 & 97,2 & 2.779 & 100 & 3.557 & 98 \\
\hline 'BRS 208' & 4.156 & 98 & 3.868 & 103 & 3.187 & 107 & 3.737 & 102 \\
\hline $\mathrm{Tm}^{2}$ & 4.216 & 100 & 3.738 & 100 & 3.007 & 100 & 3.647 & 100 \\
\hline
\end{tabular}

1 Porcentagem em relação à média das testemunhas (Tm).

${ }^{2}$ Média das testemunhas.

${ }^{3}$ Locais de Experimentação em 2003: Cachoeira do Sul, Inhacorá, Passo Fundo, Piratini, Santa Rosa, São Borja, São Luiz Gonzaga, Tapera, Tupanciretã, Vacaria, Abelardo Luz, Campos Novos, Cafelândia, Campo Mourão, Ponta Grossa, Manduri, Maracaí, Dourados e Maracajú. Total $=19$.

${ }^{4}$ Locais de Experimentação em 2004: Cachoeira do Sul, Passo Fundo, Santa Rosa, São Borja, Abelardo Luz, Campos Novos, Cafelândia, Campo Mourão, Guarapuava, Ponta Grossa, Arandu, Avaré e Manduri. Total = 13.

${ }^{5}$ Locais de Experimentação em 2005: Cachoeira do Sul, Passo Fundo, Santa Rosa, São Borja, Vacaria, Abelardo Luz, Campos Novos,

Campo Mourão, Cascavel, Guarapuava, Ponta Grossa, Manduri, Paraguaçú Paulista, Maracajú e Ponta Porã. Total = 15. 
Tabela 3 - Perfil qualitativo da cultivar de trigo ‘BRS 296’ a partir das amostras da rede de experimentação conduzida pela Embrapa Trigo no Brasil de 2003 a 2005.

\begin{tabular}{|c|c|c|c|c|c|c|}
\hline Dados & RS & SC & PR & SP & MS & Brasil \\
\hline $\mathrm{N}^{0}$ Amostras & 14 & 3 & 10 & 3 & 4 & 34 \\
\hline Força Glúten (Média) & 192 & 180 & 264 & 285 & 202 & 219 \\
\hline Número de Queda ${ }^{2}$ & 387 & 382 & 391 & 485 & 361 & 393 \\
\hline Extração $^{3}$ & 60 & 60 & 55 & 55 & 55 & 57 \\
\hline Índice de Elasticidade ${ }^{4}$ & 46 & 45 & 53 & 51 & 47 & 49 \\
\hline Tenacidade $(\mathrm{P})^{5}$ & 77 & 82 & 91 & 96 & 83 & 84 \\
\hline Extensibilidade $(\mathrm{L})^{6}$ & 82 & 69 & 91 & 90 & 78 & 84 \\
\hline Relação P/L ${ }^{7}$ & 1,0 & 1,3 & 1,1 & 1,2 & 1,1 & 1,1 \\
\hline Minolta "L" 8 & 92,7 & 93,1 & 92,4 & 93,0 & 92,2 & 92,6 \\
\hline Minolta “a” 9 & 0,0 & $-0,1$ & 0,1 & $-0,1$ & 0,0 & 0,0 \\
\hline Minolta “b” 10 & 10,0 & 10,0 & 10,3 & 10,0 & 10,5 & 10,2 \\
\hline
\end{tabular}

${ }^{1}$ Força de glúten, expressa em $10^{-4}$ Joules.

${ }^{2}$ Número de queda, expresso em segundos.

${ }^{3}$ Extração experimental de farinha, expressa em \% (base 14 \% de umidade).

${ }^{4}$ Índice de elasticidade, expresso em porcentagem.

${ }^{5}$ Tenacidade ou pressão máxima de ruptura, expressa em milímetros.

${ }^{6}$ Extensibilidade ou média da abcissa na ruptura, expressa em milímetros.

${ }^{7}$ Relação entre tenacidade e extensibilidade.

${ }^{8} \mathrm{~L}^{*}=$ luminosidade. $\mathrm{L}^{*}=100$ (branco total); $\mathrm{L}^{*}=0$ (preto total). Cor $\mathrm{L}^{*}$, Minolta.

${ }^{9} \mathrm{a}^{*}$ positivo = tendência para a cor vermelha; $\mathrm{a}^{*}$ negativo = tendência para a cor verde

${ }^{10} \mathrm{~b}^{*}$ positivo = tendência para a cor amarela; $\mathrm{b}^{*}$ negativo = tendência para a cor azul.

\section{REFERÊNCIAS}

REUNIÃO DA COMISSÃO BRASILEIRA DE PESQUISA DE TRIGO E TRITICALE, 3., 2008, Passo Fundo, RS. Informações técnicas para a safra 2009: trigo e triticale.
Passo Fundo: Comissão Brasileira de Pesquisa de Trigo, 2008. $172 \mathrm{p}$.

SOUSA, C.N.A. Cultivares de trigo indicadas para cultivo no Brasil e instituições criadoras. Passo Fundo: Embrapa Trigo, 2004. 138p. 